\title{
New-onset atrial fibrillation in critically ill patients
}

\author{
Stephanie Sibley MD FRCPC, John Muscedere MD FRCPC
}

\author{
S Sibley, J Muscedere. New-onset atrial fibrillation in critically ill \\ patients. Can Respir J 2015;22(3):179-182.
}

\begin{abstract}
New-onset atrial fibrillation is a common problem in critically ill patients, with reported incidence ranging from $5 \%$ to $46 \%$. It is associated with significant morbidity and mortality. The present review summarizes studies investigating new-onset atrial fibrillation conducted in the critical care setting, focusing on the etiology, management of the hemodynamically unstable patient, rate versus rhythm control, ischemic stroke risk and anticoagulation. Recommendations for an approach to management in the intensive care unit are drawn from the results of these studies.
\end{abstract}

Key Words: Atrial fibrillation; Critically ill; Intensive care

\section{L'apparition de fibrillation auriculaire chez des patients gravement malades}

Lapparition de fibrillation auriculaire est courante chez les patients gravement malades, l'incidence déclarée se situant entre $5 \%$ et $46 \%$. Elle s'associe à une morbidité et une mortalité importantes. La présente analyse résume des études portant sur l'apparition de fibrillation auriculaire en soins intensifs et s'attarde sur l'étiologie, la prise en charge du patient instable sur le plan hémodynamique, le contrôle de la vitesse plutôt que du rythme, le risque d'accident ischémique et l'anticoagulation. Des recommandations sur la conduite à tenir pour la prise en charge à l'unité de soins intensifs néonatales sont tirées des résultats de ces études.

Similarly, NOAF is associated with increased morbidity. In liver transplant patients, NOAF was associated with increased graft failure, renal failure and prolonged hospital stay (11). Retrospective studies suggest that patients with sepsis who develop NOAF have a greater risk for in-hospital stroke $(2.6 \%$ versus $0.6 \%)(12)$, ischemic stroke within five years $(5.3 \%$ versus $4.7 \%)$ and subsequent hospitalization for heart failure (HF) $(11.2 \%$ versus $8.2 \%$ ) (13). Moreover, NOAF may not resolve; up to $18 \%$ of patients have been described to be discharged from ICU with persistent $\mathrm{AF}(2)$.

critical care literature addressing NOA management in the ICU.

\section{ETIOLOGY}

Many conditions or risk factors are associated with the development of NOAF (Table 1). Some of these are modifiable or treatable while others are associated with the patient's diagnosis, severity of illness and life-sustaining ICU therapies. Although a prediction rule has been derived and validated to risk stratify noncardiac surgery patients for development of atrial fibrillation (AF) after major thoracic surgery (7), similar rules do not exist for general medical surgical ICU patients. While knowledge of risk factors for NOAF may be useful for identifying patients at high risk for NOAF, there are no trials investigating prophylactic therapy in the noncardiac surgery critically ill. Good ICU practices, such the avoidance of volume overload, attention to electrolyte balance and minimization of therapies, such as vasopressors, may help to reduce the occurrence of NOAF (8).

\section{MORBIDITY AND MORTALITY}

NOAF is associated with increased mortality in a variety of ICU patient populations, as demonstrated in the following studies. In a study investigating patients with sepsis, those who developed NOAF had a hospital mortality rate of $44 \%$ versus $22 \%$ for those who did not (9). In a study of surgical ICU patients, hospital mortality was $45 \%$ for individuals with NOAF versus $16 \%$ for those without (4). Finally, in a cohort of trauma patients, individuals with NOAF had a mortality rate two times that of those without; however, the standardized mortality ratio (observed/expected mortality by severity of illness) was similar in the two groups, suggesting that NOAF was a marker of more severe illness (10). The association of increased mortality in those who develop NOAF does not imply causality. Although it cannot be disproven that NOAF has attributable mortality, it is more likely that $\mathrm{NOAF}$ is a marker of disease severity.

\section{MANAGEMENT}

\section{Modifiable risk factors}

The first step in management is to address modifiable risk factors predisposing the patient to NOAF. Electrolyte abnormalities, hypoxemia, fluid overload and dehydration should be corrected. Underlying conditions should be treated promptly, including revascularization for patients with evidence of ischemia, antimicrobials for patients with sepsis and management of hyperthyroidism. Adrenergic overstimulation may contribute to the development of NOAF, and avoidance or minimization, where possible, may aid in its management or resolution.

\begin{abstract}
Hemodynamic instability
Hemodynamically unstable patients with NOAF with rapid ventricular response must be assessed to determine whether the cause of their instability is the arrhythmia or the underlying condition. If the tachycardia is a compensatory mechanism, synchronized cardioversion is unlikely to provide benefit. If hemodynamic instability is the result of AF, then restoration to normal sinus rhythm (NSR) may be helpful. Patients with life-threatening hemodynamic instability require synchronized cardioversion as per the Advanced Cardiovascular Life Support guidelines (14). Cardioversion in outpatients has a success rate of $90 \%$ (15), whereas critically ill patients have a much lower conversion rate $(35 \%)$. Of individuals who do convert, most will revert to AF within $48 \mathrm{~h}$ (16). Treatment during or immediately after with an antiarrhythmic may improve the success of cardioversion and the maintenance of NSR (17).
\end{abstract}

Rate control versus rhythm control

A systematic review and meta-analysis did not show an advantage to either a rate or rhythm control strategy for the management of NOAF 


\section{TABLE 1 \\ Risk factors for the development of new-onset atrial fibrillation*}

Patient factors

Advanced age

Male sex

Obesity

Fluid overload

Hypoxemia

Hypotension

Anemia

Acid-base abnormalities

Electrolyte abnormalities

Disease severity (Acute Physiology and Chronic Health Evaluation II score >20)

Comorbidities

Ischemic heart disease

Previous calcium channel blocker use

Intensive care unit admission diagnosis

Systemic inflammatory response syndrome

Shock

Sepsis

Heart failure with pulmonary edema

Myocardial infarction

Blunt thoracic trauma

Thoracic surgery

Intensive care unit interventions

Vasopressor use

Pulmonary artery catheter

${ }^{*}$ Risk factors and associated conditions synthesized from references 2,10,52-55

in terms of all-cause mortality, arrhythmia, cardiovascular death, embolism or major bleeding (18). Factors such as persistent AF, fewer symptoms, age $\geq 65$ years, hypertension, no history of HF, previous failure of an antiarrhythmic drug and patient preference favour rate control. Paroxysmal or NOAF, ongoing symptoms, age $<65$ years, no hypertension, HF exacerbated by AF, tachycardia-mediated cardiomyopathy and difficulty achieving rate control favour a rhythm control approach (19).

The 2014 American Heart Association (AHA)/American College of Cardiology (ACC)/ Heart Rhythm Society (HRS) practice guidelines for the management of patients with atrial fibrillation (20) recommend the use of beta-blockers or nondihydropyridine calcium channel antagonists for rate control in patients with NOAF without pre-excitation. Esmolol, propranolol and metoprolol have been shown to be effective (21-23), are available in intravenous formulations, and are titratable to avoid excessive bradycardia and hypotension.

Nondihydropyridine calcium channel antagonists, such as verapamil or diltiazem, are alternatives for patients with contraindications to betablockers. In critically ill patients, diltiazem was shown to elicit faster reduction in ventricular rate than metoprolol (23), but had a higher rate of hypotension and drug cessation compared with amiodarone (24). In emergency department patients, diltiazem was found to have faster rate control, better symptom control and decreased length of hospital stay compared with digoxin and amiodarone (25). Calcium channel blockers must be used with caution in patients with HF because of negative inotropic effects and should be avoided in patients with significant left ventricular systolic dysfunction (20).

Digoxin should not be considered as a first-line option for rate control due to its slow onset of action. It has a positive inotropic effect and may be useful in the setting of HF. Its mechanism of action is to reduce conduction through the atrioventricular node and by vagal stimulation, decreasing its utility during times of adrenergic stress. It can be safely combined with beta-blockers or calcium channel blockers $(26,27)$. Care must be taken in patients with altered renal function because continued administration may cause accumulation. Adverse effects of digoxin include atrioventricular block, ventricular arrhythmias and sinus node dysfunction.

Amiodarone has a slower onset than a beta-blocker or diltiazem $(25,28)$; however, it has been shown to successfully reduce ventricular rate and improve blood pressure in critically ill patients with AF refractory to other treatments (29). It is safe for patients with structural heart disease and has fewer negative inotropic effects than beta-blockers and calcium channel blockers (24). Long-term use of amiodarone is associated with concerning side effects, and it may contribute to pulmonary toxicity and acute respiratory distress syndrome in surgical ICU patients (30). Amiodarone use may result in cardioversion; care must be taken to anticoagulate patients at risk for thromboembolism.

Rate control may be the best option for critically ill patients because many will spontaneously convert to NSR as their acute illness resolves. In one group managed with rate control alone, $81 \%$ reverted to NSR; $19 \%$ were discharged from the ICU in AF (2). In a comparison of esmolol and diltiazem for rate control in surgical ICU patients, the conversion rate to NSR was $79 \%$ and $62 \%$, respectively (31).

Electrical cardioversion for rhythm control is safe and its effects are immediate. Complications are few and are usually related to sedation, muscle aches, burns and irritation from the electrodes. As mentioned above, the success rates of electrical cardioversion are poor compared with the outpatient population; therefore, addition of an antiarrhythmic may be required for successful conversion and maintenance of sinus rhythm.

Magnesium sulfate $\left(\mathrm{MgSO}_{4}\right)$ has been found to be effective for conversion to NSR and as a rate controlling agent (32). $\mathrm{MgSO}_{4}$ has a synergistic effect when given with digoxin in controlling ventricular rate (33). In a study in which magnesium was administered before amiodarone, many critically ill patients converted with $\mathrm{MgSO}_{4}$ alone and $90 \%$ of patients had converted within $24 \mathrm{~h}$ with both (34). Magnesium has a low side effect profile, making it a good choice as an adjunct for cardioversion (35).

A variety of other antiarrhythmics have been used for the conversion of NOAF to NSR. Amiodarone can successfully convert AF to NSR, although the time to cardioversion can be $>72 \mathrm{~h}(2)$. There is little difference between amiodarone and procainamide in critically ill patients, with conversion rates of $70 \%$ and $71 \%$, respectively (36). Procainamide has a higher rate of side effects, including hypotension, making amiodarone a safer choice unless it is contraindicated. Flecainide produced cardioversion within $1 \mathrm{~h}$ in critically ill patients with respiratory insufficiency (37). In patients with left ventricular dysfunction, heart failure and ischemic heart disease, amiodarone is associated with a low risk for proarrhythmia, whereas flecainide has been associated with increased mortality in patients with structural heart disease (38). Ibutilide is effective in converting AF to NSR in critically ill patients, but is associated with multiple side effects, QT interval prolongation and ventricular arrhythmias requiring cardioversion, limiting its utility in the ICU (39).

Propafenone and vernakalant have not been studied in the critically ill but have been successful rhythm control agents in cardiology and emergency department settings $(40,41)$. Propafenone cannot be used in patients with structural heart disease and vernakalant is contraindicated in patients with hypotension, New York Heart Association class III and IV heart failure, severe aortic stenosis and QT prolongation (42), rendering them impractical for the ICU. Dronedarone and dofetilide may also be useful for cardioversion (20), but have not been studied in an ICU population and are only available in oral formulations.

An algorithm for the management of NOAF is presented in Figure 1.

\section{STROKE RISK AND ANTICOAGULATION}

The in-hospital and five-year risk for ischemic stroke for critically ill patients with sepsis may be elevated based on retrospective chart reviews $(12,13,43)$. There has only been one retrospective observational study of anticoagulation for AF in the ICU, which showed no 


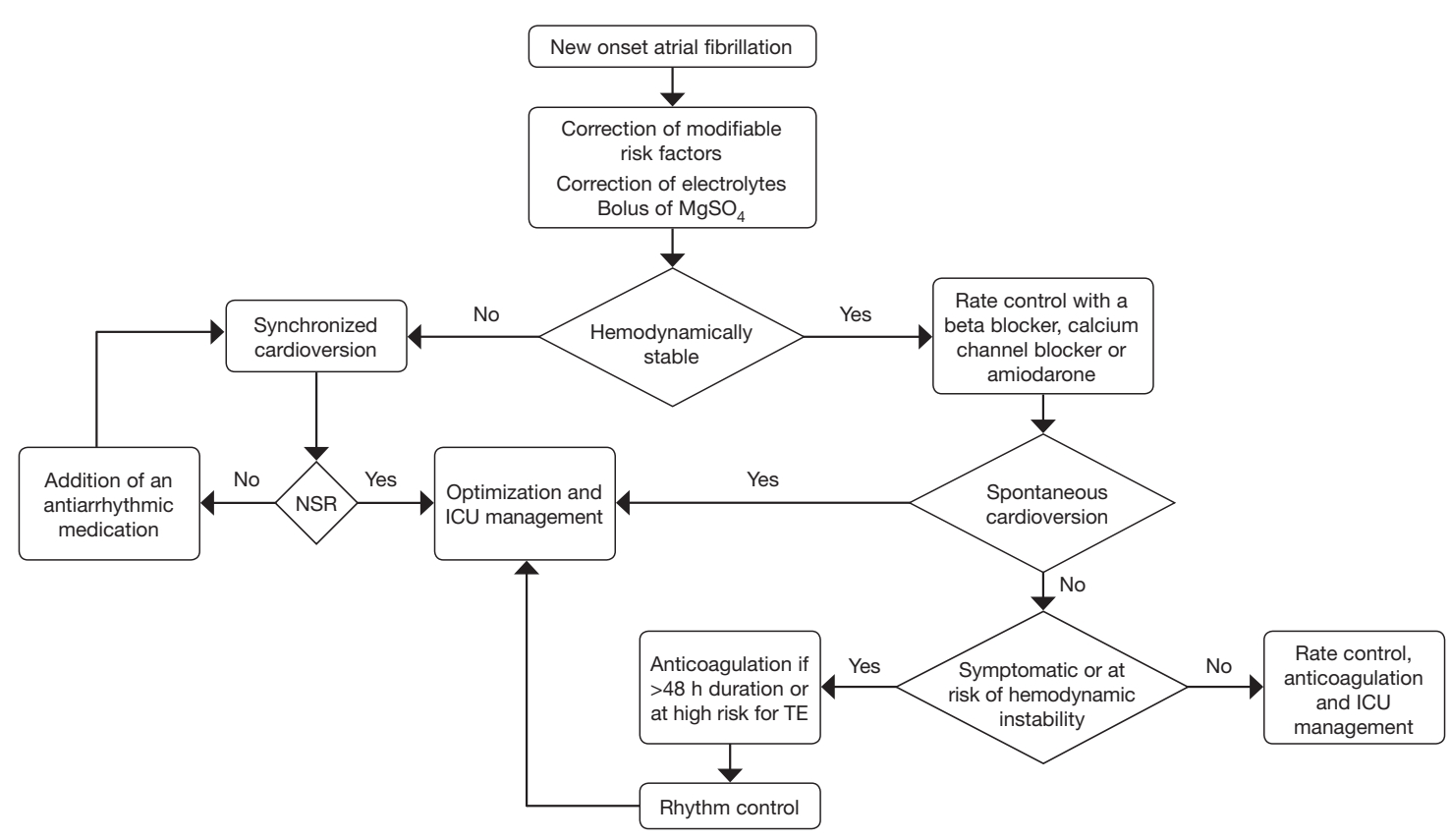

Figure 1) Management of new-onset atrial fibrillation in critically ill patients. ICU Intensive care unit; $\mathrm{MgSO}_{4}$ Magnesium sulfate; NSR Normal sinus rhythm; TE Thromboembolism

difference in survival but increased minor bleeding events in anticoagulated patients (44). CHADS2, CHADS-VaSC $(45,46)$ and HAS-BLED (47) scores assess one-year thromboembolic stroke and bleeding risk but have not been validated in ICU populations.

In patients who have persistent or paroxysmal $\mathrm{AF}>48 \mathrm{~h}$, anticoagulation should be initiated. If the duration is $>48 \mathrm{~h}$ or unknown, patients should undergo three weeks of anticoagulation before cardioversion followed by four weeks of anticoagulation. Alternatively, patients can undergo transesophageal echocardiography to rule out left atrial thrombus before cardioversion, followed by four weeks of anticoagulation (48). Patients with $\mathrm{AF}<48 \mathrm{~h}$ who are at low risk for thromboembolic events can be cardioverted safely without anticoagulation (49). Patients at high risk for thromboembolic events should have anticoagulation started before cardioversion (20). The risk for thromboembolism is highest within $72 \mathrm{~h}$ of cardioversion and most events occur within 10 days $(50,51)$. Patients discharged from the ICU with ongoing $\mathrm{AF}$ require long-term anticoagulation.

Anticoagulation is a challenge in the ICU given the potential need for urgent surgery or procedures, traumatic injuries and risk for coagulopathy. Unfractionated heparin is the drug of choice for ICU patients given its short half-life and reversibility with protamine. Warfarin can be considered for stable patients who have an intact gastrointestinal tract and are unlikely to require further procedures. The new anticoagulants such as dabigitran, rivaroxaban and apixiban have not been studied in ICU patients, but the lack of reversibility will likely limit their utility in this setting.

\section{CONCLUSIONS}

There is a lack of high-quality evidence to guide the management of critically ill patient with NOAF. Prompt treatment of underlying medical conditions and correction of modifiable risk factors is the first step. Hemodynamically unstable patients should undergo synchronized cardioversion. The choice of a rate versus rhythm control strategy should be based on patient factors, comorbidities and underlying medical conditions, but there is no evidence favouring one approach over the other. Rate control with a beta-blocker is the first option for hemodynamically stable patients, with use of a calcium channel blocker if beta blockade is contraindicated an alternative. Amiodarone should be reserved for AF refractory to beta-blockers and calcium channel blockers. If a rhythm control approach is used, appropriate anticoagulation should be instituted for AF with a duration $>48 \mathrm{~h}$ and for patients at high risk for thromboembolism. $\mathrm{MgSO}_{4}$ should be initiated first because it may achieve rhythm control alone and will act synergistically with other antiarrhythmic drugs. Amiodarone is as effective as other antiarrhythmic drugs in achieving cardioversion, although its side effect profile favours it over other antiarrhythmics. If required, unfractionated heparin is the anticoagulant of choice. Further studies are needed to determine the attributable morbidity and mortality resulting from NOAF and optimal therapy of this common arrhythmia in critically ill patients.

ACKNOWLEDGEMENTS: SS conducted the literature review and wrote the manuscript. JM critically revised the manuscript.

DISCLOSURES: None to report.

\section{REFERENCES}

1. Salman S, Bajwa A, Gajic O, et al. Paroxysmal atrial fibrillation in critically ill patients with sepsis. J Intensive Care Med 2008;23:178-83.

2. Kanji S, Williamson DR, Yaghchi BM, et al. Epidemiology and management of atrial fibrillation in medical and noncardiac surgical adult intensive care unit patients. J Crit Care 2012;27:e321-8.

3. Seguin P, Launey Y. Atrial fibrillation is not just an artefact in the ICU. Crit Care 2010;14:182.

4. Chen AY, Sokol SS, Kress JP, et al. New-onset atrial fibrillation is an independent predictor of mortality in medical intensive care unit patients. Ann Pharmacother 2015;49:523-7.

5. Rivero-Ayerza M, Scholte Op Reimer W, Lenzen M, et al. New-onset atrial fibrillation is an independent predictor of in-hospital mortality in hospitalized heart failure patients: Results of the Euroheart Failure Survey. Eur Heart J 2008;29:1618-24.

6. Reinelt P, Karth GD, Geppert A, et al. Incidence and type of cardiac arrhythmias in critically ill patients: A single center experience in a medical-cardiological ICU. Intensive Care Med 2001;27:1466-73.

7. Passman RS, Gingold DS, Amar D, et al. Prediction rule for atrial fibrillation after major noncardiac thoracic surgery. Ann Thorac Surg 2005;79:1698-703.

8. Asfar P, Meziani F, Hamel JF, et al. High versus low blood-pressure target in patients with septic shock. N Engl J Med 2014;370:1583-93. 
9. Meierhenrich R, Steinhilber E, Eggermann C, et al. Incidence and prognostic impact of new-onset atrial fibrillation in patients with septic shock: A prospective observational study. Crit Care 2010;14:R108.

10. Seguin P, Laviolle B, Maurice A, et al. Atrial fibrillation in trauma patients requiring intensive care. Intensive Care Med 2006;32:398-404.

11. Xia VW, Worapot A, Huang S, et al. Postoperative atrial fibrillation in liver transplantation. Am J Transplant 2015;15:687-694.

12. Walkey AJ, Wiener RS, Ghobrial JM, et al. Incident stroke and mortality associated with new-onset atrial fibrillation in patients hospitalized with severe sepsis. JAMA 2011;306:2248-54.

13. Walkey AJ, Hammill BG, Curtis LH, et al. Long-term outcomes following development of new-onset atrial fibrillation during sepsis. Chest 2014;146:1187-95

14. Neumar RW, Otto CW, Link MS, et al. Part 8: Adult advanced cardiovascular life support: 2010 American Heart Association guidelines for cardiopulmonary resuscitation and emergency cardiovascular care. Circulation 2010;122(18 Suppl 3):S729-67.

15. Joglar JA, Kowal RC. Electrical cardioversion of atrial fibrillation. Cardiol Clin 2004:22:101-11.

16. Mayr A, Ritsch N, Knotzer H, et al. Effectiveness of direct-current cardioversion for treatment of supraventricular tachyarrhythmias, in particular atrial fibrillation, in surgical intensive care patients. Crit Care Med 2003;31:401-5.

17. Oral H, Souza JJ, Michaud GF, et al. Facilitating transthoracic cardioversion of atrial fibrillation with ibutilide pretreatment. N Engl J Med 1999;340:1849-54

18. Caldeira D, David C, Sampaio C. Rate versus rhythm control in atrial fibrillation and clinical outcomes: Updated systematic review and meta-analysis of randomized controlled trials. Arch Cardiovasc Dis 2012;105:226-38.

19. Gillis AM, Verma A, Talajic M, et al. Canadian Cardiovascular Society atrial fibrillation guidelines 2010: Rate and rhythm management. Can J Cardiol 2011;27:47-59.

20. January CT, Wann LS, Alpert JS, et al. 2014 AHA/ACC/HRS Guideline for the management of patients with atrial fibrillation: A Report of the American College of Cardiology/American Heart Association Task Force on practice guidelines and the Heart Rhythm Society. J Am Coll Cardiol 2014;64:e1-76.

21. Abrams J, Allen J, Allin D, et al. Efficacy and safety of esmolol vs propranolol in the treatment of supraventricular tachyarrhythmias: A multicenter double-blind clinical trial. Am Heart J 1985;110:913-22.

22. Platia EV, Michelson EL, Porterfield JK, et al. Esmolol versus verapamil in the acute treatment of atrial fibrillation or atrial flutter. Am J Cardiol 1989;63:925-9.

23. Demircan C, Cikriklar HI, Engindeniz Z, et al. Comparison of the effectiveness of intravenous diltiazem and metoprolol in the management of rapid ventricular rate in atrial fibrillation. Emerg Med J 2005;22:411-4.

24. Delle Karth G, Geppert A, Neunteufl T, et al. Amiodarone versus diltiazem for rate control in critically ill patients with atrial tachyarrhythmias. Crit Care Med 2001;29:1149-53.

25. Siu CW, Lau CP, Lee WL, et al. Intravenous diltiazem is superior to intravenous amiodarone or digoxin for achieving ventricular rate control in patients with acute uncomplicated atrial fibrillation. Crit Care Med 2009;37:2174-9.

26. Koh KK, Kwon KS, Park HB, et al. Efficacy and safety of digoxin alone and in combination with low-dose diltiazem or betaxolol to control ventricular rate in chronic atrial fibrillation. Am J Cardiol 1995; 75:88-90.

27. Kochiadakis GE, Kanoupakis EM, Kalebubas MD, et al. Sotalol vs metoprolol for ventricular rate control in patients with chronic atrial fibrillation who have undergone digitalization: A single-blinded crossover study. Europace 2001;3:73-9.

28. Hofmann R, Steinwender C, Kammler J, et al. Effects of a high dose intravenous bolus amiodarone in patients with atrial fibrillation and a rapid ventricular rate. Int J Cardiol 2006;110:27-32.

29. Clemo HF, Wood MA, Gilligan DM, et al. Intravenous amiodarone for acute heart rate control in the critically ill patient with atrial tachyarrhythmias. Am J Cardiol 1998;81:594-8.

30. Ashrafian H, Davey P. Is amiodarone an underrecognized cause of acute respiratory failure in the ICU? Chest 2001;120:275-82.

31. Balser JR, Martinez EA, Winters BD, et al. Beta-adrenergic blockade accelerates conversion of postoperative supraventricular tachyarrhythmias. Anesthesiology 1998;89:1052-9.

32. Moran JL, Gallagher J, Peake SL, et al. Parenteral magnesium sulfate versus amiodarone in the therapy of atrial tachyarrhythmias:

A prospective, randomized study. Crit Care Med 1995;23:1816-24.
33. Ho KM, Sheridan DJ, Paterson T. Use of intravenous magnesium to treat acute onset atrial fibrillation: A meta-analysis. Heart 2007;93:1433-40.

34. Sleeswijk ME, Tulleken JE, Van Noord T, et al. Efficacy of magnesiumamiodarone step-up scheme in critically ill patients with new-onset atrial fibrillation: Aprospective observational study. J Intensive Care Med 2008;23:61-6.

35. Ganga HV, Noyes A, White CM, et al. Magnesium adjunctive therapy in atrial arrhythmias. Pacing Clin Electrophysiol 2013;36:1308-18.

36. Kanji S, Stewart R, Fergusson DA, et al. Treatment of new-onset atrial fibrillation in noncardiac intensive care unit patients: A systematic review of randomized controlled trials. Crit Care Med 2008;36:1620-4.

37. Barranco F, Sanchez M, Rodriguez J, et al. Efficacy of flecainide in patients with supraventricular arrhythmias and respiratory insufficiency. Intensive Care Med 1994;20:42-4.

38. Echt DS, Liebson PR, Mitchell LB, et al. Mortality and morbidity in patients receiving encainide, flecainide, or placebo. The Cardiac Arrhythmia Suppression Trial. N Engl J Med 1991;324:781-8.

39. Varriale P, Sedighi A. Acute management of atrial fibrillation and atrial flutter in the critical care unit: Should it be ibutilide? Clin Cardiol 2000;23:265-68.

40. Camm AJ, Capucci A, Hohnloser SH, et al. A randomized activecontrolled study comparing the efficacy and safety of vernakalant to amiodarone in recent-onset atrial fibrillation.

J Am Coll Cardiol 2011;57:313-21.

41. Freemantle N, Lafuente-Lafuente C, Mitchell S, et al. Mixed treatment comparison of dronedarone, amiodarone, sotalol, flecainide, and propafenone, for the management of atrial fibrillation. Europace 2011;13:329-45.

42. Heldal M, Atar D. Pharmacological conversion of recent-onset atrial fibrillation: A systematic review. Scand Cardiovasc J 2013;(Suppl)47:2-10.

43. Walkey AJ, Greiner MA, Heckbert SR, et al. Atrial fibrillation among medicare beneficiaries hospitalized with sepsis: Incidence and risk factors. Am Heart J 2013;165:949-55.

44. Darwish OS, Strube S, Nguyen HM, et al. Challenges of anticoagulation for atrial fibrillation in patients with severe sepsis. Ann Pharmacother 2013:47:1266-71.

45. Lip GY, Frison L, Halperin JL, et al. Identifying patients at high risk for stroke despite anticoagulation: A comparison of contemporary stroke risk stratification schemes in an anticoagulated atrial fibrillation cohort. Stroke 2010;4:2731-8.

46. Lip GY, Nieuwlaat R, Pisters R, et al. Refining clinical risk stratification for predicting stroke and thromboembolism in atrial fibrillation using a novel risk factor-based approach: The Euro Heart Survey on Atrial Fibrillation. Chest 2010;137:263-72.

47. Pisters R, Lane DA, Nieuwlaat R, et al. A novel user-friendly score (HAS-BLED) to assess 1-year risk of major bleeding in patients with atrial fibrillation: The Euro Heart Survey. Chest 2010;138:1093-100.

48. Klein AL, Grimm RA, Murray RD, et al. Use of transesophageal echocardiography to guide cardioversion in patients with atrial fibrillation. N Engl J Med 2001;344:1411-20.

49. Weigner MJ, Thomas LR, Patel U, et al. Early cardioversion of atrial fibrillation facilitated by transesophageal echocardiography: Short-term safety and impact on maintenance of sinus rhythm at 1 year. Am J Med 2001;110:694-702.

50. Airaksinen KE, Gronberg T, Nuotio I, et al. Thromboembolic complications after cardioversion of acute atrial fibrillation: The Fincv (Finnish Cardioversion) study. J Am Coll Cardiol 2013;62:1187-92.

51. Berger M, Schweitzer P. Timing of thromboembolic events after electrical cardioversion of atrial fibrillation or flutter: A retrospective analysis. Am J Cardiol 1998;82:1545-7;A1548.

52. Knotzer H, Mayr A, Ulmer $\mathrm{H}$, et al. Tachyarrhythmias in a surgical intensive care unit: A case-controlled epidemiologic study. Intensive Care Med 2000;26:908-14

53. Kuipers S, Klein Klouwenberg P, Cremer OL. Incidence, risk factors and outcomes of new-onset atrial fibrillation in patients with sepsis: A systematic review. Crit Care 2014;18:688.

54. Arora S, Lang I, Nayyar V, et al. Atrial fibrillation in a tertiary care multidisciplinary intensive care unit - incidence and risk factors. Anaesth Intensive Care 2007;35:707-13.

55. Seguin P, Signouret T, Laviolle B, et al. Incidence and risk factors of atrial fibrillation in a surgical intensive care unit.

Crit Care Med 2004;32:722-6. 


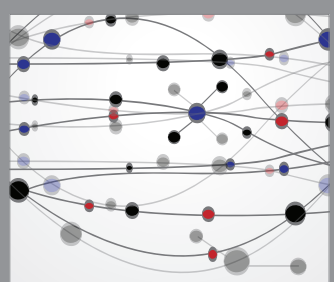

The Scientific World Journal
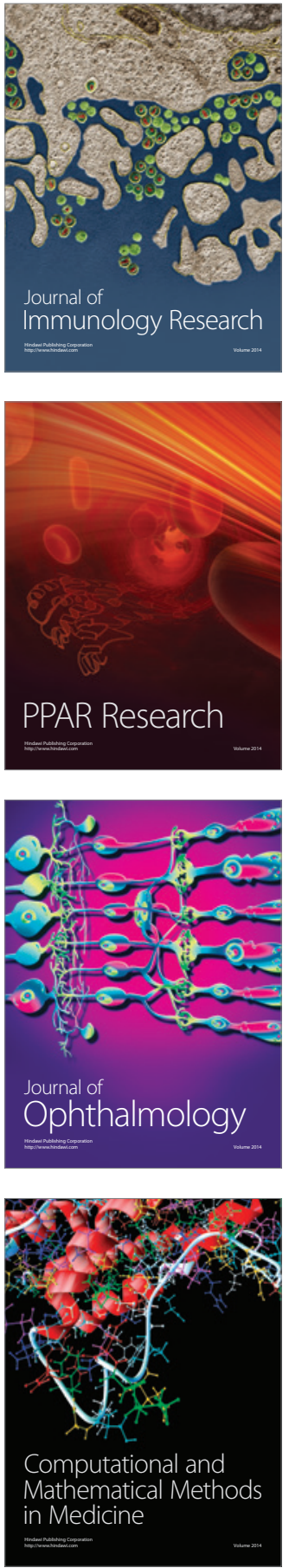

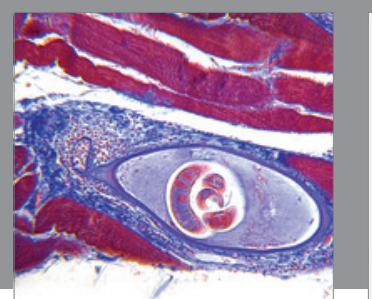

Gastroenterology Research and Practice

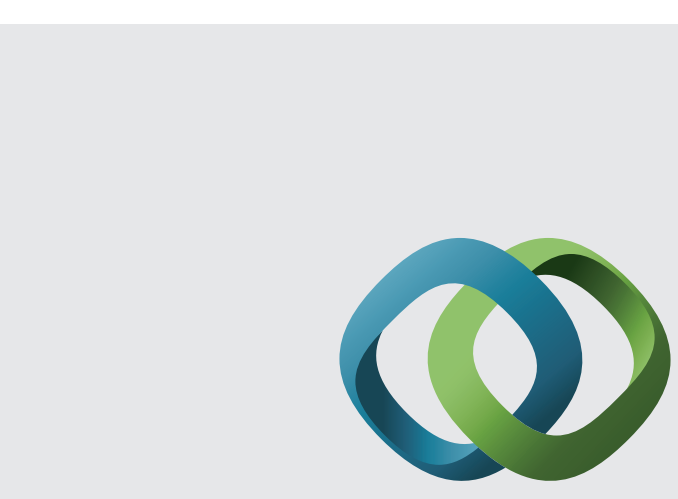

\section{Hindawi}

Submit your manuscripts at

http://www.hindawi.com
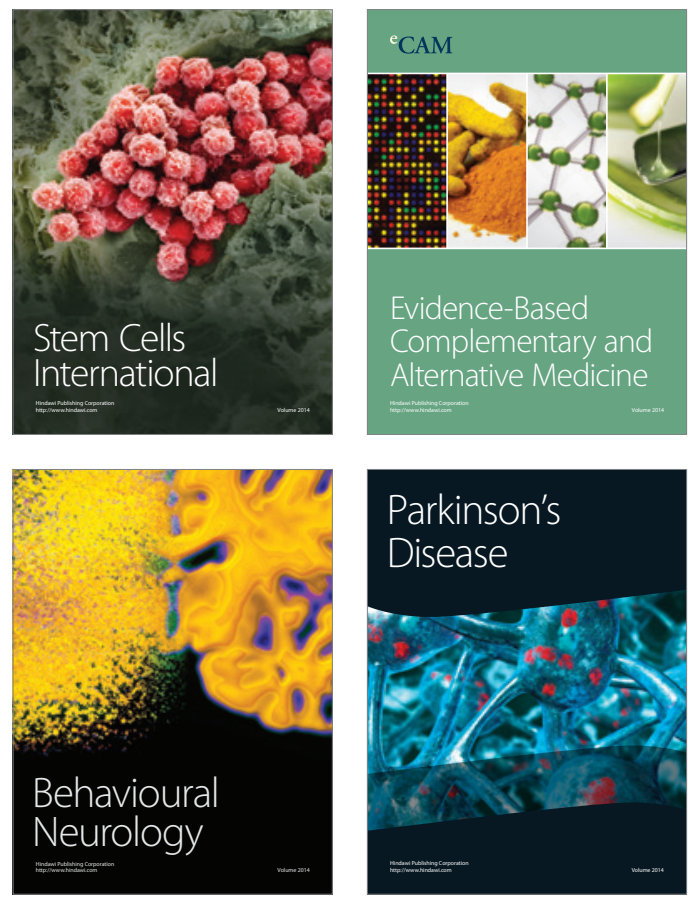
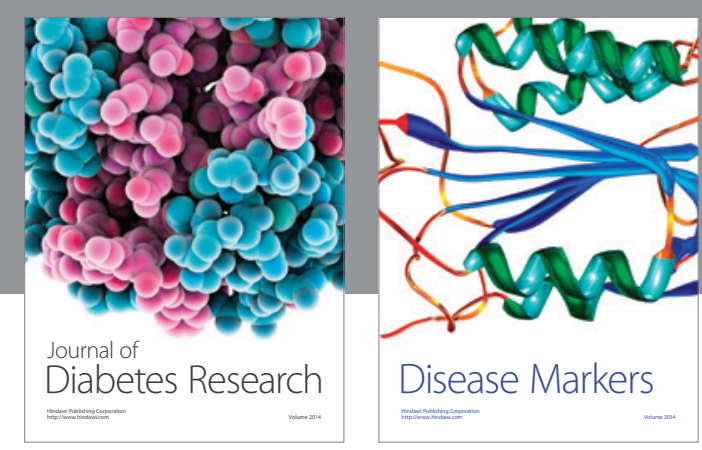

Disease Markers
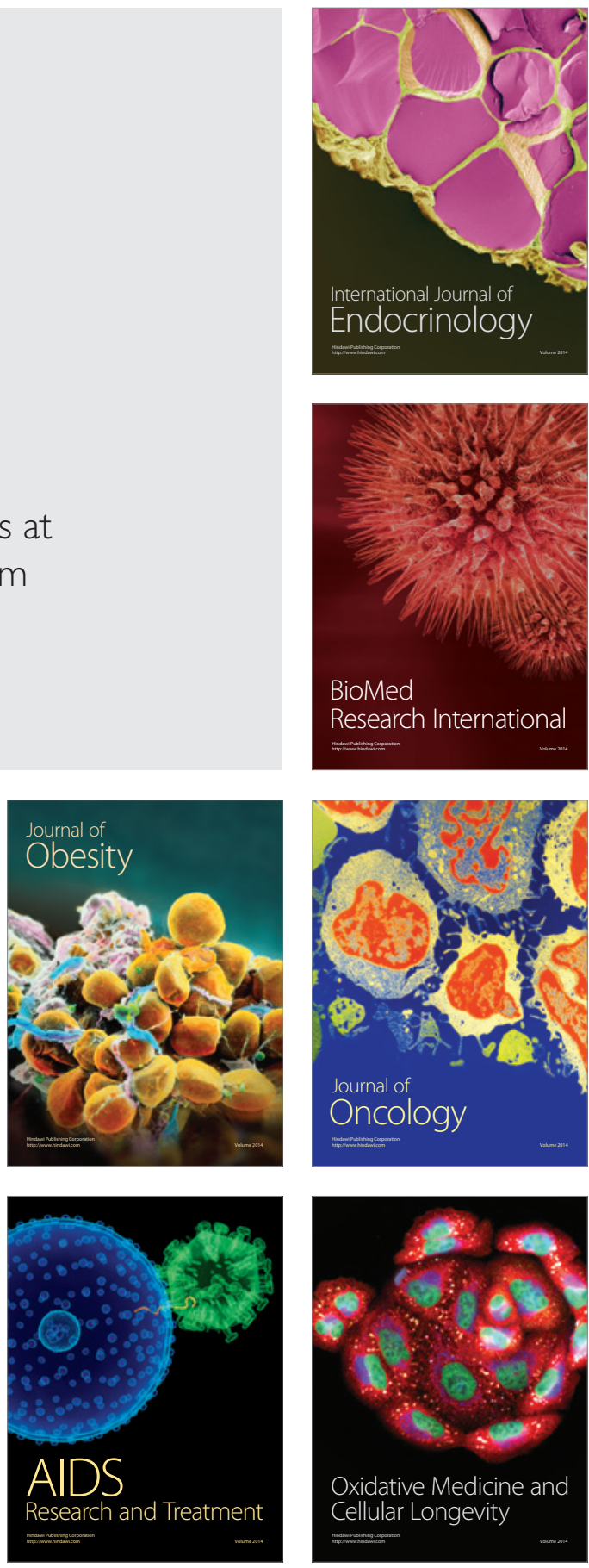